\title{
Protective Effects of Oral Microencapsulated Mycoplasma hyopneumoniae Vaccine Prepared by Co-Spray Drying Method
}

\author{
J. H. LIN ${ }^{1)}$, C. N. WENG ${ }^{2)}$, C. W. LIAO ${ }^{2)}$, K. S. YEH ${ }^{2)}$ and M. J. PAN ${ }^{1) *}$ \\ ${ }^{1)}$ Department of Veterinary Medicine, National Taiwan University, 142 Chou-san Rd., Taipei and ${ }^{2)}$ Division of Animal Medicine, Animal \\ Technology Institute Taiwan, PO Box 23, Chunan, Miaoli, Taiwan
}

(Received 30 January 2002/Accepted 8 October 2002)

ABSTRACT. The efficacy of Mycoplasma hyopneumoniae oral vaccine was investigated in microsphere dosage form. A co-spray drying process was used to apply an encapsulating material, Eudragit L30 D-55, to microspheres containing Mycoplasma hyopneumoniae antigens. The microspheres were generally effective (>93\%) with protein release at $\mathrm{pH} 7.4$, but almost none were released at $\mathrm{pH} 1.2$, for 3 $\mathrm{hr}$ in an in vitro dissolution test. An SPF-swine model was used to evaluate the effectiveness of the microspheres as an oral vaccine, and the related immune responses. The serum's systemic IgG against $M$. hyopneumoniae was evoked by ELISA analysis, after a 2nd immunization of all pigs. The vaccinated groups' mean lesion score was significantly lower after the Mycoplasma hyopneumoniae challenge than that of the nonvaccinated/challenged groups $(\mathrm{P}<0.05)$. This study strongly suggests that the oral microspheres vaccine prepared by a co-spray drying method can provide effective protection against $M$. hyopneumoniae infection in pigs.

KEY WORDS: co-spray drying, microsphere, Mycoplasma hyopneumoniae, oral vaccine.

J. Vet. Med. Sci. 65(1): 69-74, 2003

Mycoplasma hyopneumoniae is widely recognized as a potent pathogen for mycoplasmal pneumonia in swine [2], colonizing the respiratory epithelia and compromising integrity by inducing an inflammatory response [20]. The pathogen also causes significant economic losses by reducing body weight and prolonging periods between feeds [22]. Although some drugs and antibiotics are effective in vitro against $M$. hyopneumoniae, reducing the disease's clinical signs [12], they have not yet been proven effective in eliminating the pathogen in vivo. Vaccination is an essential strategy in controlling mycoplasmal pneumonia. M. hyopneumoniae infects the ciliated epithelial cells of the respiratory tract [6], and a mucosal immune response may therefore be important in the prevention and control of $M$. hyopneumoniae-induced pneumonia [23]. The concept of a common mucosal immune system has been supported by several oral immunization reports $[8,13]$. Numerous experimental systems have proven that oral immunization can induce antibody secretion into the mucus on these surfaces $[8,16,18]$, and is almost completely restricted to the secretory form of IgA. Oral immunization causes this $\operatorname{IgA}$ antibody to be secreted from the GALT to distant mucosal tissue, including the salivary, mammary, respiratory, intestine and genital mucosal tissue, protecting these areas from pathogen invasion [5, 14].

Microspheres have recently received widespread interest as vehicles for the controlled release of drug or bioactive agents; resisting degradation in gastric acid, they can release drugs in the intestines [1]. Oral antigen delivery by $\mathrm{pH}-$ dependent microspheres can improve local and systemic immune responses $[4,16]$, serving as a potent mucosal

\footnotetext{
* Correspondence to: Pan, M. J., Professor of Microbiology, Department of Veterinary Medicine, National Taiwan University, 142 Chou-san Rd., Taipei, Taiwan ROC.
}

immunogen. It is essential to develop a new, simple and effective vaccine process. Microsphere oral vaccines have been previously developed in our laboratory via a novel cospray-drying process [16]. Current research uses the cospray drying method, with the $M$. hyopneumoniae as a model antigen encapsulated with an enteric-coating material of Aqua-coat [16] or Eudragit L30 D-55. The co-spray drying method used for microsphere preparation is more convenient and reliable than solvent evaporation, and is practical for future use. Research herein contributes to the development of a future mycoplasma oral vaccine.

\section{MATERIALS AND METHODS}

Preparation of microspheres: The PRIT-5 M. hyopneumoniae strain isolated by the Animal Technology Institute, Taiwan, ROC, was cultured in Friis medium [9] and treated as in our previous investigation [17]. The culture was harvested when the medium's O.D. 550 value was between 0.07 and 0.09 . After the addition of $0.2 \%$ formalin, the culture was incubated at $37^{\circ} \mathrm{C}$ with shaking for $1 \mathrm{hr}$, then stored at $4^{\circ} \mathrm{C}$ overnight [25].

The $\mathrm{pH}$-dependent enteric-coating material Eudragit L30 D-55 (Aqueous acrylic polymer dispersion) was used for microsphere preparation. The co-spray drying method involved mixing $M$. hyopneumoniae $(125 \mathrm{ml})$ in a solution containing water $(47.5 \mathrm{ml})$, encapsulated material (Eudragit L30 D-55, $62.5 \mathrm{ml}$ ), and additives (Talc $4.2 \mathrm{~g}, 87 \%$ Glycerol $8.4 \mathrm{ml}$ ). The $M$. hyopneumoniae and water-based entericcoating material solution was fed into the heated chamber of a spray dryer. Droplets containing polymer and additives were pumped through a high-speed disk and then sprayed into the chamber with warm air. The microspheres were then dried, and harvested with a cyclone. Disk speed was adjusted to $30,000 \mathrm{rpm}$ and the inlet air temperature was 
held between $40^{\circ} \mathrm{C}$ and $50^{\circ} \mathrm{C}$ for a few seconds, before cooling at $25^{\circ} \mathrm{C}$ to $35^{\circ} \mathrm{C}$. A model L- 8 spray dryer (from Ohkawara Kakohki Co., Ltd., Yokohama, Japan) was used as described in a previous report [15].

In vitro dissolution: A $\mathrm{pH}$ condition simulating the gastrointestinal tract's environment was modified via a procedure mimicking the USP XXII enteric-coated drug release method (1990). The dissolution of enteric-coated microspheres for various $\mathrm{pH}$ levels at $37^{\circ} \mathrm{C}$ was then determined. The release of $M$. hyopneumoniae from the co-spray dried microsphere was assisted by a paddle rotating dissolution apparatus (DT-6 Shin Kwang, Taiwan). Microspheres were incubated in $500 \mathrm{ml}$ of acid buffer ( $\mathrm{HCl}$ containing $0.2 \% \mathrm{w} /$ $\mathrm{v} \mathrm{NaCl}, \mathrm{pH} 1.2$ ) at a rotation speed of $100 \mathrm{rpm}$ for $2 \mathrm{hr}$; the $\mathrm{pH}$ was then adjusted to 7.4 by $\mathrm{Na}_{3} \mathrm{PO}_{4}[1,7,21]$. A different $\mathrm{pH}$ was used for the dissolution test in this procedure. The sample was removed at various time intervals and centrifuged at 6,600 $\mathrm{g}$ for $1 \mathrm{~min}$ after which the protein content of the supernatant was measured with a BCA protein microassay kit. The microspheres' protein concentration was determined and the encapsulated efficiency of the protein content was calculated [i.e., the M. hyopneumoniae quantity (after in vitro dissolution) divided by the total $M$. hyopneumoniae mass (before encapsulation) (wt/wt)]. Each sample was analyzed in triplicate.

Encapsulating efficiency of Eudragit L30 D-55: Microspheres were dispersed in a phosphate buffered saline (PBS, $\mathrm{pH}$ 7.4) under continual rotation at $4^{\circ} \mathrm{C}$ overnight and the supernatant was then collected. To extract protein from the microspheres prepared with Eudragit L30 D-55, supernatant from the in vitro dissolution was mixed with 4 volumes of $100 \%$ acetone and 5\% SDS (final concentration) for $1 \mathrm{hr}$ at $-20^{\circ} \mathrm{C}$ and then centrifuged at $12,000 \mathrm{rpm}$ for $30 \mathrm{~min}$ [7]. The pellet was dried and redissolved in $50 \mu \mathrm{l}$ PBS for protein analysis, SDS-PAGE, and Western-blotting.

SDS-PAGE analysis of the microspheres' unencapsulated and encapsulated $M$. hyopneumoniae extract was undertaken as described above. The gel was stained with Coomassie brilliant blue $(0.1 \% \mathrm{w} / \mathrm{v}$ with methanol) for 15 min after electrophoresis. A destaining solution (methanol : acetic acid: pure water=50:40:10) was added to the gel for overnight washing. Gel was also electrotransferred for Western-blotting after electrophoresis, and protein was electrotransferred to a nitrocellulose membrane. The membrane was blocked overnight with PBS containing 5\% skim milk. Hyperimmune rabbit anti-M. hyopneumoniae antiserum was added to PBS containing $0.5 \%$ skim milk, and the membranes were shaken for $2 \mathrm{hr}$. After three PBST washes (PBS containing $0.05 \%$ Tween 20 ), the membranes were incubated for $1.5 \mathrm{hr}$ with goat anti-rabbit IgG conjugated alkaline phosphate. The blot was given three PBST washes and developed in an AP substrate buffer containing nitro blue tetrazolium (NBT) and 5-bromo-4chloro-3-indolyl phosphate (BCIP).

Animals and experiment design: Thirty 6-week-old cross breed piglets were purchased from the Taiwan Animal Technology Institute's SPF experimental farm. The piglets were housed in an SPF facility with aseptic feed and water, and randomly divided by weight into five groups: Eu (microspheres prepared with enteric-coating polymer Eudragit L30 D55), IM (intramuscular), Mix (instramuscular + oral vaccine), nonvaccinated/challenged (NV/C), and nonchallenged (NC). The first day of the study was designated day 0 . Microspheres were suspended in a $5 \%$ acetic acid solution, and the resulting antigen solution was put into the pigs' mouths via a syringe attached to the mouth. Group Eu was received $3 \times 10^{9} \mathrm{CCU}$ (color change units) of the $M$. hyopneumoniae oral vaccine on day 0 , which was boosted on days 10 and 20 . The intramuscular vaccines were prepared from PRIT-5 of M. hyopneumoniae grown for 48 to $72 \mathrm{hr}$ in Friis medium. The vaccine contained $10^{9} \mathrm{CCU}$ of viable organisms before treatment with $0.2 \%$ formaldehyde. Group IM (intramuscular) received this M. hyopneumoniae vaccine with aluminium hydroxide as an adjuvant via intramuscular injection on days 0,10 and 20. Group Mix received an intramuscular injection on day 0 , and $M$. hyopneumoniae oral vaccine on days 10 and 20, whereas groups $\mathrm{NV} / \mathrm{C}$ and $\mathrm{NC}$ were fed a placebo. All 24 piglets in groups $\mathrm{Eu}, \mathrm{IM}, \mathrm{Mix}$ and NV/C were challenged on day 30 with $5 \mathrm{~m}$ of $10 \%$ pneumonic lung homogenate suspension containing $10^{7} \mathrm{CCU}$ of $M$. hyopneumoniae [26], via intubation of the trachea.

On days 0, 10, 20 and 30, blood, feces, nasal and saliva samples were obtained and held overnight at $4{ }^{\circ} \mathrm{C}$, after which the serum was isolated and stored at $-20^{\circ} \mathrm{C}$. Feces, nasal and saliva swabs were collected, placed in $0.5 \mathrm{ml}$ washing buffer [PBS containing 5\%(w/w) Phenylmethanesulfonyl fluoride (PMSF), 0.2\%(w/w) trypsin soybean inhibitor, $0.2 \%(\mathrm{w} / \mathrm{w})$ gelatin], and spun at $6,000 \mathrm{~g}$ for $1 \mathrm{~min}$. The washing buffer collected was maintained at $-20^{\circ} \mathrm{C}$ [19]. All the pigs were slaughtered, and their lungs removed and examined for lesions on day $68[11,26]$. Portions of lung were collected to isolate $M$. hyopneumoniae and bacteria [23].

Enzyme-linked immunosorbent assay (ELISA): Each well of microtiter plates was coated with $100 \mu \mathrm{l}$ of $M$. hyopneumoniae lysate solution at a concentration of $1 \mu \mathrm{g}$, in a $0.1 \mathrm{M}$ sodium carbonate/bicarbonate buffer ( $\mathrm{pH} 9.6)$ and stored overnight at $4^{\circ} \mathrm{C}$ [27]. After suction, $100 \mu l$ of PBS containing $0.5 \%$ skim milk was used to block the antigen on the plates, which were then incubated at $37^{\circ} \mathrm{C}$ for $30 \mathrm{~min}$ and washed 5 times with PBST (PBS containing $0.05 \%$ Tween 20). Phosphate milk buffer (PBS containing $0.05 \%$ skim milk) was used as a diluent for all samples collected. For antibody quantitative analysis, a standard curve of enzymeimmunoassay values was obtained with dilutions of a swine immunoglobulin reference serum. The 3 -fold dilutions $(6$, $2,0.6,0.2,0.06,0.02,0.006 \mu \mathrm{g} / \mathrm{m} l$ of $\mathrm{IgG}$ or $1.4,0.48,0.14$, $0.048,0.014,0.0046,0.0015 \mu \mathrm{g} / \mathrm{m} l$ of $\mathrm{IgA}$ ) were introduced and coated in triplicate on a plate [15]. Unknown sample values were obtained from the standard curves. One unit $/ \mathrm{m} l$ of antibodies was defined by the absorbance value of $1 \mu \mathrm{g} /$ $\mathrm{m} l$ of immunoglobulin reference, and one $\mathrm{mU} / \mathrm{m} l$ of antibodies was defined by the absorbance value of $1 \mathrm{ng} / \mathrm{ml}$ of 
immunoglobulin reference. Standard curves ranging from 0.06 to 6 units of $\mathrm{IgG}$ and from 0.014 to 1.4 units of $\mathrm{IgA}$ against the absorbance value, could therefore be obtained [12]. The initial serum and swab washing fluid dilution were 1:200 and 1:10, respectively. One hundred $\mu l$ of diluted samples were then added to wells and kept at $37^{\circ} \mathrm{C}$ for $1.5 \mathrm{hr}$. After five PBST washings, goat-anti-pig IgG and IgA alkaline phosphatase (Bethyl Laboratory, Montgomery, AL, USA) were diluted 1:2500 with a conjugating buffer (0.05 M Tris $\mathrm{HCl}, 0.15 \mathrm{M} \mathrm{NaCl}, 0.1 \mathrm{mM}$ EDTA, 0.05\% Tween 20), added to wells, and incubated for $1.5 \mathrm{hr}$. Alkaline phosphatase substrate [PNPP (p-nitrophenyl phosphate)] buffer was then added, and after $30 \mathrm{~min}$ of incubation, the optical density at $405 \mathrm{~nm}$ was analyzed with an ELISA reader.

Statistical analyses: Results were analyzed by ANOVA, and significant differences between the treatment group and time course (day) were tested at $\mathrm{P}<0.05$.

\section{RESULTS}

In vitro dissolution: When the Eudragit microspheres were placed in a $\mathrm{pH} 1.2$ solution, simulating the gastric environment, less than $20 \%$ of the protein was released at $37^{\circ} \mathrm{C}$ during $2 \mathrm{hr}$ of incubation. In a simulated intestinal environment ( $\mathrm{pH}$ 7.4) however, most of the $M$. hyopneumoniae antigens in the microspheres were released between 0.5 and 4 hr. Figure 1A shows the cumulative protein release percentages over time for both $\mathrm{pH} 1.2$ and $\mathrm{pH}$ 7.4. Figure 1B shows the cumulative protein release percentages over time for different $\mathrm{pH}$ environments.

Encapsulated efficiency of Eudragit L30 D-55: After the spray-drying process and in vitro dissolution, the untreated control protein was compared to the protein extracted from microspheres by SDS-PAGE and Western-blotting. SDSPAGE and Western-blotting graphs revealed that bands before encapsulation were similar to the bands after encapsulation (Fig. 2A, 2B). Most protein was encapsulated into microspheres and released into simulated intestine fluid, and no significant difference between the untreated and extracted protein was found. This phenomenon suggests that the protein antigenicity did not change after encapsulation.

Swine evaluation: The vaccinated groups exhibited an increased humoral IgG response to M. hyopneumoniae, which increased over the course of vaccinations (Table 1). The vaccinated groups' specific immunoglobulin gradually increased compared to the NV/C group. Only a low level of

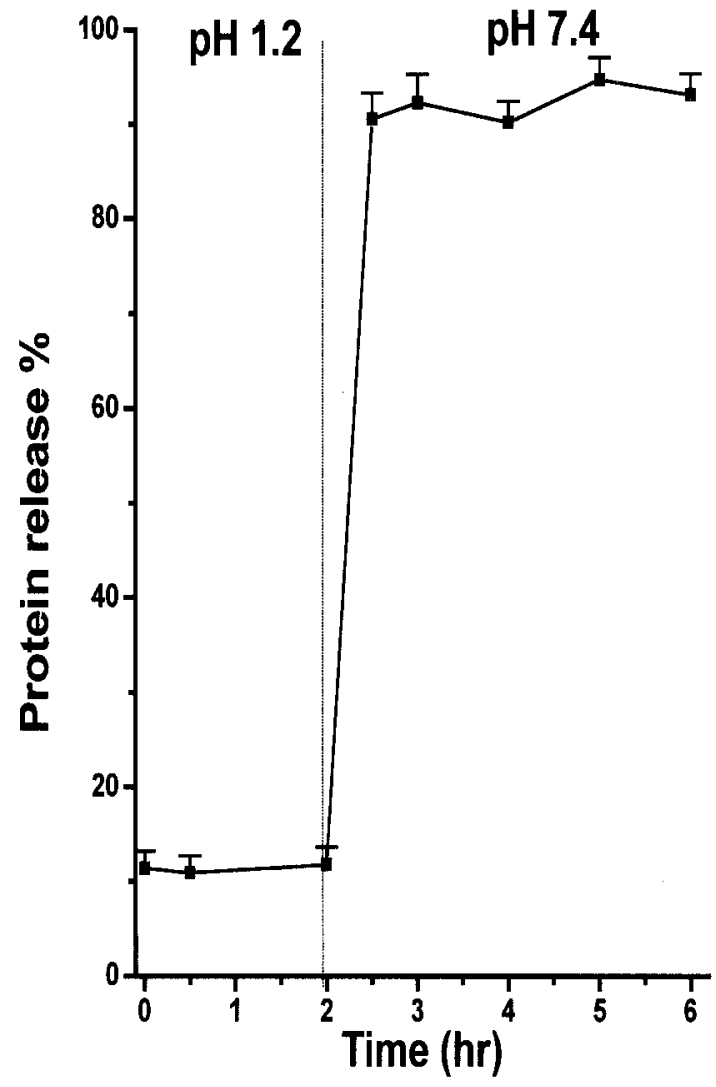

A

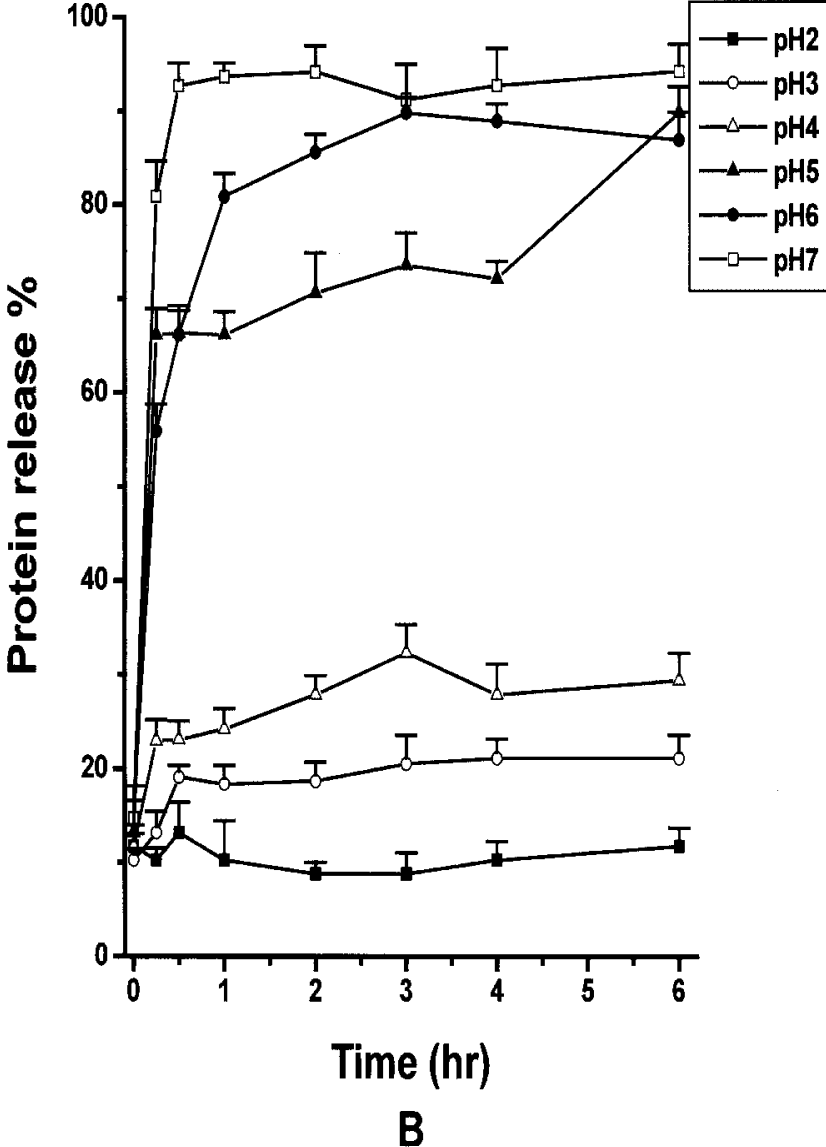

Fig. 1. Effect of $\mathrm{pH}$ on M. hyopneumoniae release at $\mathrm{pH} 1.2$ and 7.4 (A), different $\mathrm{pH}$ (B). 


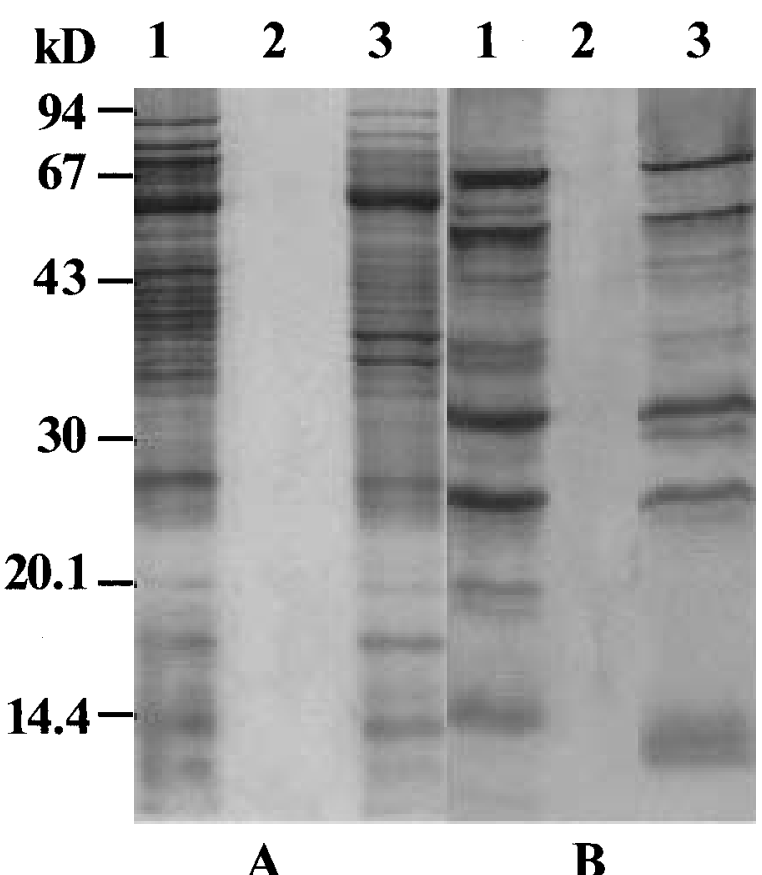

Fig. 2. SDS-PAGE (A) and Western-blotting (B) analysis of $M$. hyopneumoniae, extracted from microspheres in simulated gastric and intestinal fluid. Lane 1, untreated M. hyopneumoniae; lane 2, microspheres prepared from Eudragit L30 D-55 at $\mathrm{pH} 1.2$ for $2 \mathrm{hr}$ incubation $\left(37^{\circ} \mathrm{C}\right)$; lane 3 , microspheres prepared from Eudragit L30 D-55 at pH 7.4 for $2 \mathrm{hr}$ incubation $\left(37^{\circ} \mathrm{C}\right)$.
M. hyopneumoniae-specific IgA was detected in serum, saliva, feces, and nasal wash on days 0,10 and 20 (data not shown), which was significantly different from that seen on day 30 in the NV/C group $(\mathrm{P}<0.05)$ (Table 2$).$

The NV/C group exhibited such clinical signs as a cough and rough hair after challenging. Typical lung lesions were observed in pigs from the NV/C group during necropsy, which also had higher pneumonic scores than the three vaccinated groups. M. hyopneumoniae was cultured from lung specimens of 23/24 challenged pigs (Table 3); no bacteria were detected in any of the specimens. SPF swine model challenge tests also revealed that oral and intramuscular vaccinations provided similar protection against lung lesion formation.

\section{DISCUSSION}

Protection against bacteria causing respiratory disease has long been known to have a stronger correlation with IgA antibodies in local secretions than with serum antibodies alone $[3,23,24]$. It is widely believed that successful mucosal immunization requires mucosal antigen administration. The two main paths proposed for antigen delivery to the most relevant mucosal tissue are the intranasal and peroral, though the peroral route is the more convenient. A high induction IgA response is often achieved through direct immunization via GALT, therefore antigen oral delivery by $\mathrm{pH}$-dependent microspheres is a potent mucosal immunogen, enhancing local and systemic immune responses [4].

The spray drying method resulted in partial instability or

Table 1. Levels of immunoglobulin $\mathrm{G}$ in serum after three M. hyopneumoniae vaccinations by different routes of administration in pigs $(\mathrm{n}=6)$

\begin{tabular}{ccccc}
\hline & \multicolumn{3}{c}{ Mean of M. hyopneumoniae-specific IgG value $(\mathrm{U} / \mathrm{m} l)$} \\
\cline { 2 - 4 } Group & Day0 & Day10 & Day20 & Day30 \\
\hline Eu & $0.57 \pm 0.29^{\mathrm{a}, \mathrm{A})}$ & $1.14 \pm 0.35^{\mathrm{a}), \mathrm{A})}$ & $15.26 \pm 3.97^{\mathrm{b}), \mathrm{B})}$ & $48.07 \pm 9.62^{\mathrm{c}), \mathrm{B})}$ \\
IM & $0.43 \pm 0.20^{\mathrm{a}, \mathrm{A})}$ & $7.42 \pm 0.94^{\mathrm{b}), \mathrm{B})}$ & $28.20 \pm 4.49^{\mathrm{c}), \mathrm{C})}$ & $83.58 \pm 11.46^{\mathrm{d}), \mathrm{D})}$ \\
Mix (IM + Eu) & $0.48 \pm 0.22^{\mathrm{a}), \mathrm{A})}$ & $6.56 \pm 1.13^{\mathrm{b}), \mathrm{B})}$ & $24.21 \pm 3.09^{\mathrm{c}, \mathrm{C})}$ & $68.86 \pm 7.20^{\mathrm{d}), \mathrm{C})}$ \\
NV/C & $0.43 \pm 0.32^{\mathrm{a}, \mathrm{A})}$ & $0.52 \pm 0.34^{\mathrm{a}), \mathrm{A})}$ & $1.22 \pm 0.42^{\mathrm{a}, \mathrm{A})}$ & $1.02 \pm 0.44^{\mathrm{a}), \mathrm{A})}$ \\
NC & $0.47 \pm 0.26^{\mathrm{a}, \mathrm{A})}$ & $0.68 \pm 0.35^{\mathrm{a}), \mathrm{b}), \mathrm{A})}$ & $1.10 \pm 0.47^{\mathrm{a}), \mathrm{b}), \mathrm{A})}$ & $1.36 \pm 0.48^{\mathrm{b}), \mathrm{A})}$ \\
\hline
\end{tabular}

a)-d) Within a row, means with different superscript differ significantly $(\mathrm{P}<0.05)$.

A)-D) Within a column, means with different superscript differ significantly $(\mathrm{P}<0.05)$.

Table 2. Levels of immunoglobulin A in serum, feces, nasal and saliva after three M. hyopneumoniae vaccinations by different routes of administration in pigs $(n=6)$ on day 30

\begin{tabular}{|c|c|c|c|c|}
\hline \multirow[b]{2}{*}{ Group } & \multicolumn{4}{|c|}{ Mean of $M$. hyopneumoniae-specific $\operatorname{IgA}$ value $(\mathrm{mU} / \mathrm{m} l)$} \\
\hline & Serum & Feces & Nasal & Salivary \\
\hline $\mathrm{Eu}$ & $258.23 \pm 19.46^{\mathrm{c}), \mathrm{C})}$ & $24.74 \pm 7.64^{\mathrm{a}), \mathrm{C})}$ & $18.34 \pm 10.54^{\mathrm{a}), \mathrm{B})}$ & $104.23 \pm 10.45^{\mathrm{b}), \mathrm{C})}$ \\
\hline $\mathrm{IM}$ & $99.12 \pm 5.48^{\mathrm{c}), \mathrm{B})}$ & $10.27 \pm 6.49^{\mathrm{a}), \mathrm{A}), \mathrm{B})}$ & $5.08 \pm 4.12^{\mathrm{a}), \mathrm{A}), \mathrm{B})}$ & $22.10 \pm 4.12^{\mathrm{b}), \mathrm{B})}$ \\
\hline $\operatorname{Mix}(\mathrm{IM}+\mathrm{Eu})$ & $277.84 \pm 22.15^{\mathrm{c}), \mathrm{C})}$ & $28.35 \pm 6.23^{\mathrm{a}, \mathrm{C})}$ & $16.61 \pm 12.00^{\mathrm{a}), \mathrm{B})}$ & $136.13 \pm 14.29^{\mathrm{b}), \mathrm{D})}$ \\
\hline $\mathrm{NV} / \mathrm{C}$ & $14.42 \pm 2.92^{\mathrm{b}), \mathrm{A})}$ & $3.44 \pm 2.52^{\mathrm{a}), \mathrm{A})}$ & $2.54 \pm 2.12^{\mathrm{a}, \mathrm{A})}$ & $2.46 \pm 1.79^{\mathrm{a}), \mathrm{A})}$ \\
\hline $\mathrm{NC}$ & $10.12 \pm 2.70^{\mathrm{b}), \mathrm{A})}$ & $2.90 \pm 2.13^{\mathrm{a}), \mathrm{A})}$ & $2.26 \pm 1.36^{\mathrm{a}, \mathrm{A})}$ & $2.90 \pm 2.48^{\mathrm{a}), \mathrm{A})}$ \\
\hline
\end{tabular}

a)-d)Within a row, means with different superscript differ significantly $(\mathrm{P}<0.05)$.

A)-D)Within a column, means with different superscript differ significantly $(\mathrm{P}<0.05)$. 
Table 3. Severity of lung lesions and incidences of M. hyopneumoniae isolated from specimens of pig lungs $(n=6)$ on day 68

\begin{tabular}{ccc}
\hline Group & $\begin{array}{c}\text { Score of lung surface with pneumonic } \\
\text { lesions (mean } \pm \text { SEM) }\end{array}$ & $\begin{array}{c}\text { Number of } \text { M. hyopneumonia/0.5 g of } \\
\text { lung (Mean } \pm \text { SEM) }\end{array}$ \\
\hline $\mathrm{Eu}$ & $4.67 \pm 1.07^{\mathrm{C})}$ & $5.00 \pm 0.63$ \\
$\mathrm{IM}$ & $4.17 \pm 1.17^{\mathrm{C})}$ & $4.67 \pm 1.03$ \\
$\mathrm{Mix}(\mathrm{IM}+\mathrm{Eu})$ & $1.33 \pm 1.37^{\mathrm{B})}$ & $3.67 \pm 1.87$ \\
$\mathrm{NV} / \mathrm{C}$ & $13.83 \pm 2.56^{\mathrm{D})}$ & $7.50 \pm 2.07$ \\
$\mathrm{NC}$ & $0^{\mathrm{A})}$ & 0 \\
\hline
\end{tabular}

A)-D)Within a column, means with different superscripts differ significantly $(\mathrm{P}<0.05)$.

degradation of the entrapped antigen, perhaps because the protein was exposed to physical force that changed its structure and antigenicity, causing incomplete antigen release [10]. This phenomenon raises the question of whether the antigen encapsulation was selective or non-selective. Formulation profiles similar to untreated $M$. hyopneumoniae were found in the SDS-PAGE graph, indicating that protein encapsulation was non-selective. A Western-blotting graph revealed that protein from microspheres prepared by the cospray drying process had the same major bands as untreated $M$. hyopneumoniae, indicating that $M$. hyopneumoniae antigenicity is not changed by the co-spray drying process, and therefore this formulation can be used in in vivo studies with swine.

This work reveals that co-spray drying is suitable for the production of antigen loaded microspheres prepared from enteric-coating materials. Microspheres prepared by Eudragit L30 D-55 exhibited pH-dependent release characteristics, with the initial burst of $M$. hyopneumoniae release relating to the buffer $\mathrm{pH}$. Protein was released from microspheres at $\mathrm{pH} 7.4$, but not at $\mathrm{pH} 1.2$, indicating M. hyopneumoniae remained intact in gastric acid but disintegrated in the intestine. The $\mathrm{pH}$ range of the slaughtered pigs' intestines was 1.4-3.7 in the duodenum and 4.6-7.8 in the ileum. Figure 1B shows the rupture of microspheres near the ileum where Peyer's patches are extensively located. This may partially explain the enhanced immune response and protective effect elicited from antigens in the intestine. Various factors, including antigen protection under low $\mathrm{pH}$, controlled antigen release, and the effective attachment of antigens to the Peyer's patches, may explain the greater efficacy of this formulation. Microspheres prepared by Eudragit had a good yield, and the formulation should be promising in enteric dosage form.

Vaccinated groups displayed more obvious immune responses than the NV/C group, indicating that microspheres prepared via co-spray drying can be used as an oral vaccine and elicit a significant immune response. The concept of a common mucosal immune system has been supported by several oral immunization studies $[8,13,16]$. Delgado et al. demonstrated induction of specific IgA antibodies at various mucosal sites via oral administration in mice, showing that oral administration of antigens can effectively induce antibodies through Peyer's patches [7].
Pigs also show some signs of protection after intramuscular inoculation with formalin-inactivated $M$. hyopneumoniae vaccine, and a booster inoculation with the same vaccine onto the mucosal surface of Peyer's patches via surgical operation [26]. This information indicates that the primary goal of mucosal immunization is to induce secreted antibodies into mucosal surfaces, both at the immunization site and at distant surfaces, and that serum $\operatorname{IgA}$ is a crucial factor in protecting pigs from M. hyopneumoniae infection. Far less anti-M. hyopneumoniae IgA was measured in feces and nasal swabs than in saliva, perhaps because IgA was digested by a feces enzyme. The great amount of anti- $M$. hyopneumoniae $\mathrm{IgA}$ in saliva suggests local production of anti-M. hyopneumoniae $\operatorname{Ig} \mathrm{A}$ in the mucosa, although it could also be due to preferential transport of serum IgA across the epithelium indicating that anti-M. hyopneumoniae IgA circulates in the blood prior to entering the far distant mucosal system. Results shown in Table 3 reveal that lungs treated with oral vaccine had significantly lower lesion scores than NV/C groups, indicating that oral vaccine microspheres protect the pig's respiratory system from $M$. hyopneumoniae. Protection against clinical mycoplasmal pneumonia was not directly related to serum antibody concentrations induced by $M$. hyopneumoniae vaccination [24]. The mixed group had an improved immune response or protective effect compared to the Eu group. It appears that anti$M$. hyopneumoniae $\mathrm{IgG}$ still has a function in M. hyopneumoniae vaccination. The results of this study suggest however, that a vaccine administered both intramuscularly and orally results in an enhanced local mucosal immune response, demonstrated by the significantly increased $M$. hyopneumoniae-specific IgG and IgA concentrations in the vaccinated group.

The present study has had some success in evoking systemic and mucosal immune responses through peroral administration of microspheres. A proposed co-spray drying method which aerosolizes an emulsion of enteric-coating polymer and its additives in a single-step process could easily be scaled up, and warrants further investigation. Microspheres can be formulated as a tablet and mixed with animals' food for use in the field, providing an easy method for oral vaccine mass administration and protecting the $M$. hyopneumoniae from the acidic environment. This method would substantially reduce the vaccination labor costs. In 
conclusion, $M$. hyopneumoniae serves as a model antigen, and encapsulated with Eudragit L30 D-55 as an entericcoating material, and by using the co-spray drying method to prepare the microspheres, it is convenient and reliable, and is suitable for future use.

ACKNOWLEDGMENTS. The authors would like to thank the National Science Council of the Republic of China, Taiwan for financially supporting this research under Contract No. NSC-89-2317-B059-001.

\section{REFERENCES}

1. Akiyama, Y., Yoshioka, M., Horibe, H., Hira, S., Kitmori, N. and Toguchi, H. 1994. pH-independent controlled-release microspheres using polyglycerol esters of fatty acids. $J$. Pharm. Sci. 83: 1600-1607.

2. Amass, S. F., Clark, L. K.,van Alstine, W. G., Bowersock, T. L., Murphy, D. A., Knox, K. E. and Albregts, S. R. 1994. Interaction of Mycoplasma hyopneumoniae and Pasteurella multocida infections in swine. J. Am. Vet. Med. Assoc. 204: 102107.

3. Bosse, J. T., Johnson, R. P., Nemec, M. and Rosendal, S. 1992. Protective local and systemic antibody responses of swine exposed to an aerosol of Actinobacillus pleuropneumoniae serotype 1. Infect. Immun. 60: 479-484.

4. Challacombe, S. J., Rahman, D., Jeffery, H., Davis, S. S. and O'Hagan, D. T. 1992. Enhanced secretory IgA and systemic IgG antibody responses after oral immunization with biodegradable microparticles containing antigen. Immunology $\mathbf{7 6}$ : 164-168.

5. Czerkinsky, C., Svennerholm, A. M., Quiding, M., Jonsson, R. and Holmgren, J. 1991. Antibody-producin cells in peripheral blood and salivary glands after oral cholera vaccination of humans. Infect. Immun. 59: 996-1001.

6. DeBey, M. C., Jacobson, C. D. and Ross, R. F. 1992. Histochemical and morphologic changes of porcine airway epithelial cells in response to infection with Mycoplasma hyopneumoniae. Am. J. Vet. Res. 53: 1705-1710.

7. Delgado, A., Lavelle, E. C., Hartshorne, M. and Davis, S. S. 1999. PLG microparticles stabilized using enteric coating polymers as oral vaccine delivery systems. Vaccine 17: 2927-2938.

8. Eldridge, J. H., Hammond, C. J., Meulbroek, J. A., Staas, J.K., Gilley, R. M. and Tice, T. R. 1990. Controlled vaccine release in the gut-associated lymphoid tissues. I. Orally administered biodegradable microspheres target the Peyer's patches. J. Control. Release 11: 205-214.

9. Friis, N. F. 1975. Some recommendations concerning primary isolation of Mycoplasma suipneumoniae and Mycoplasma flocculare a survey. Nord. Vet. Med. 27: 337-339.

10. Gander, B., Wehrli, E., Alder, R. and Merkle, H. P. 1995. Quality improvement of spray-dried, protein-loaded D,L-PLA microspheres by appropriate polymer solvent selection. $J$. Microencapsul. 12: 83-97.

11. Goodwin, R. F. and Whittlestone, P. 1973. Enzootic pneumonia of pigs: immunization attempts inoculating Mycoplasma suipneumoniae antigen by various routes and with different adjuvants. Bri. Vet. J. 129: 456-464.

12. Hannan, P. C., Windsor, H. M. and Ripley, P. H. 1997. In vitro susceptibilities of recent field isolates of Mycoplasma hyopneumoniae and Mycoplasma hyosynoviae to valnemulin (Econor), tiamulin and enrofloxacin and the in vitro develop- ment of resistance to certain antimicrobial agents in $\mathrm{Myco}$ plasma hyopneumoniae. Res. Vet. Sci. 63: 157-160.

13. Husband, A. J. 1987. Perspectives in mucosal immunity: a ruminant model. Vet. Immunol. Immunopathol. 17: 357-365.

14. Jertborn, M., Svennerholm, A. M. and Holmgren, J. 1986. Saliva, breast milk, and serum antibody responses as indirect measures of intestinal immunity after oral cholera vaccination or natural disease. J. Clin. Microbiol. 24: 203-209.

15. Kulvanich, P. and Leesawat, P. 1996. Release characteristics of the matrices prepared from co-spray dried theophylline and ethylcellulose with/without channeling agents. Pro. Inter. Sym. Control. Release Bio. Mater. 23: 143-144.

16. Liao, C. W., Cheng, I. C., Yeh, K. S., Lin, F. Y. and Weng, C. N. 2001. Release characteristics of microspheres prepared by co-spray drying Actinobacillus pleuropneumoniae antigens and aqueous ethyl-cellulose dispersion. J. Microencapsul. 18: 285297.

17. Lin, S. Y., Tzan, Y. L. and Lee, C. J. 1991. Preparation of enteric-coated microspheres of Mycoplasma hyopneumoniae vaccine with cellulose acetate phthalate: I. Formation condition and micromeritic properties. J. Microencapsul. 8: 317-325.

18. Mestecky, J. 1987. The common mucosal immune system and current strategies for induction of immune responses in external secretions. J. Clin. Immunol. 7: 265-276.

19. Offit, P. A., Khoury, C. A., Moser, C. A., Clark, H. F., Kim, J. E. and Speaker, T. J. 1994. Enhancement of rotavirus immunogenicity by microencapsulation. Virology 203: 134-143.

20. Okada, M., Asai, T., Ono, M., Sakano, T. and Sato, S. 2000. Cytological and immunological changes in bronchoalveolar lavage fluid and histological observation of lung lesions in pigs immunized with Mycoplasma hyopneumoniae inactivated vaccine prepared from broth culture supernate. Vaccine 18: 2825 31.

21. Schwendeman, S. P., Tobio, M., Joworowicz, M., Alonso, M. J. and Langer, R. 1998. New strategies for the microencapsulation of tetanus vaccine. J. Microencapsul. 15: 299-318.

22. Stipkovits, L., Miller, D., Glavits, R., Fodor, L. and Burch, D. 2001. Treatment of pigs experimentally infected with Mycoplasma hyopneumoniae, Pasteurella multocida, and Actinobacillus pleuropneumoniae with various antibiotics. Can. J. Vet. Res. 65: 213-222.

23. Thacker, E. L., Thacker, B. L., Kuhn, M., Hawkins, P. A. and Waters, W. R. 2000. Evaluation of local and systemic immune responses induced by intramuscular infection of a Mycoplasma hyopneumoniae bacterin to pigs. Am. J. Vet. Res. 61: 1384 1389.

24. Thacker, E. L., Thacker, B. J. and Boettcher, T. B. 1998. Comparison of antibody production, lymphocyte stimulation and production induced by four commercial Mycoplasma hyopneumoniae bacterins. Swine Health Prod. 6: 107-112.

25. Tzan, Y. L., Weng, C. N., Lee, C. J. and Lin, S. Y. 1989. Determination of antigenic characteristics of Mycoplasma hyopneumoniae by enzyme-linked immunosorbent assay. I. The establishment and performance of ELISA. J. Chi. Soc. Vet. Sci. 15: 193-198.

26. Weng, C. N., Tzan, Y. L., Liu, S. Y. and Lee, C. J. 1992. Protective effects of an oral microencapsulated Mycoplasma hyopneumoniae vaccine against experimental infection in pigs. Res. Vet. Sci. 53: 42-46.

27. Weng, C. N., Lin, S. Y., Tzan, Y. L. and Lee, C. J.1991. Determination of antigenic characteristics and stability of Mycoplasma hyopneumoniae. Biotechnol. Prog. 7: 69-71. 